\title{
Reversal of Rotating Behavior in the Domestic Fowl by Neural Grafting
}

\author{
Joseph Yanai ${ }^{1}$, David Shamir ${ }^{1}$ and William F. Silverman ${ }^{2}$ \\ ${ }^{1}$ The Ross Laboratory for Studies in Neural Birth Defects, Department of Anatomy and Embryology, \\ Hebrew University, Hadassah Medical School, Jerusalem, and ${ }^{2}$ Unit of Morphology, Faculty of Health \\ Sciences, Ben-Gurion University, Beer Sheva, Israel
}

The present study was designed to establish a model of rotational behavior and its reversal through the use of neural grafting in the domestic fowl. Young sexually mature males of the chicken breed Black Silkie were utilized in this study. An initial experiment was conducted in order to select the appropriate drug for the induction of locomotor activity. Apomorphine induced locomotor activity in naive animals at a level of more than 100 times that found in control animals. The drug was effective even at low dosages and reached its maximal effect at 10 $\mathrm{mg} / \mathrm{kg}$. On the other hand, unlike the results of similar treatment in rodents, amphetamine at any dosage level (from 0.25 to $40 \mathrm{mg} / \mathrm{kg}$ ) produced no effect on locomotor activity in domestic fowl.

In a subsequent experiment, approximately half of the subjects were given unilateral stereotaxic injections of 6-hydroxydopamine (6OHDA, $20 \mu \mathrm{g} /$ animal) into the avian equivalent of the substantia nigra; control animals received the vehicle injection. The animals were injected i.p. with apomorphine or amphetamine in order to establish the appropriate drug which would best produce rotational behavior in this species. Apomorphine injections to the lesioned animals $(3 \mathrm{mg} / \mathrm{kg})$ produced strong contralateral rotations (5.5 rotations/minute). Again, however, unlike results found in rodents, amphetamine in the doses used did not produce rotational behavior in chickens.

Animals treated with 6-OHDA received embryonic (day 7) transplants of substantia nigra cell suspensions into the striatum; the respective sham-transplanted controls received the vehicle solution. The presence of grafted dopamine neurons in the grafted chickens was confirmed by tyrosine hydroxylase (TH) immunocyto- chemistry. As is shown in Table 1, all transplanted, 6-OHDA lesioned animals ceased rotating within 30 days after implantation, while sham-transplanted, 6-OHDA lesioned chickens continued to rotate normally. Even increasing the dose to $5 \mathrm{mg} / \mathrm{kg}$, which caused an even higher rotation score in the non-grafted lesioned animals, failed to produce rotations in the grafted animals. These findings extend the existing model for reversal of 6-OHDA-induced rotational behavior by transplantation, to include avian species. The appropriate drug to be used for the induction of the behavior (apomorphine) and the optimal day for the removal of the embryonic donor tissue (day 7) are suggested. The main advantage of the avian model is the convenient use of an unlimited number of embryos at the exact age required by the experimental design.

\section{TABLE 1}

Apomorphine induced rotational behavior in the domestic fowl following 6-OHDA lesion of the avian substantia nigra and subsequent transplantation of embryonic dopaminergic cells to the striatum

\begin{tabular}{lccc}
\hline $\begin{array}{l}\text { treatment } \\
\text { group }\end{array}$ & $\begin{array}{c}\text { before } \\
\text { transplantation }\end{array}$ & 1 week & 1 month \\
\hline control & $6.08 \pm 0.55$ & $6.20 \pm 0.45$ & $6.10 \pm 0.50$ \\
transplanted & $6.08 \pm 0.85$ & $5.72 \pm 1.04$ & $0.50 \pm 0.35$ \\
\hline
\end{tabular}

Scores are mean number of contralateral rotations $( \pm S E M), n=6$ in each group.

${ }^{*} \mathrm{p}<0.001$ for the difference from the transplanted group.

Supported in part by USPHS grant DA-6670 

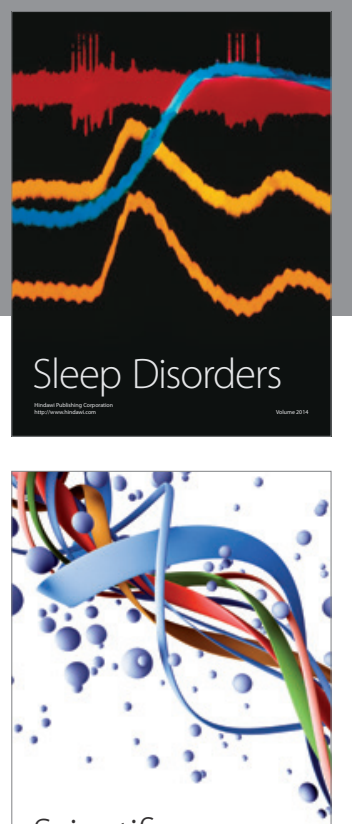

Scientifica
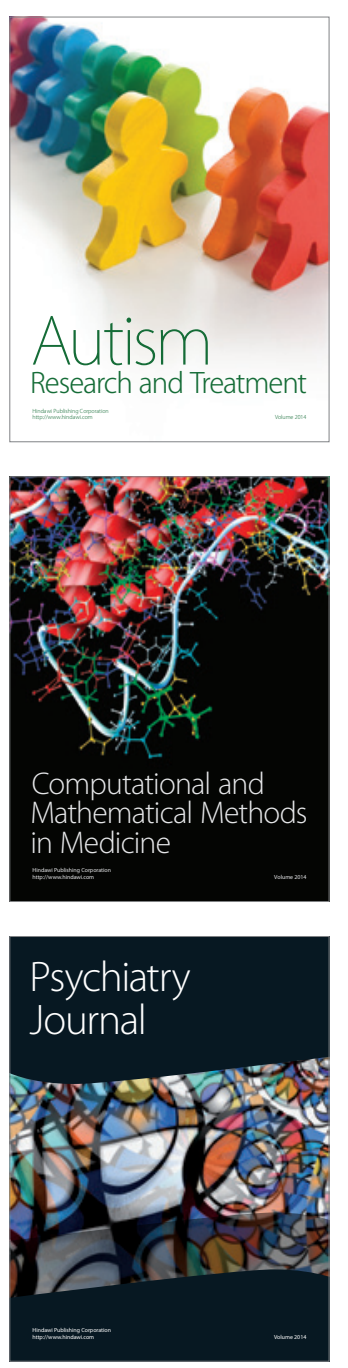
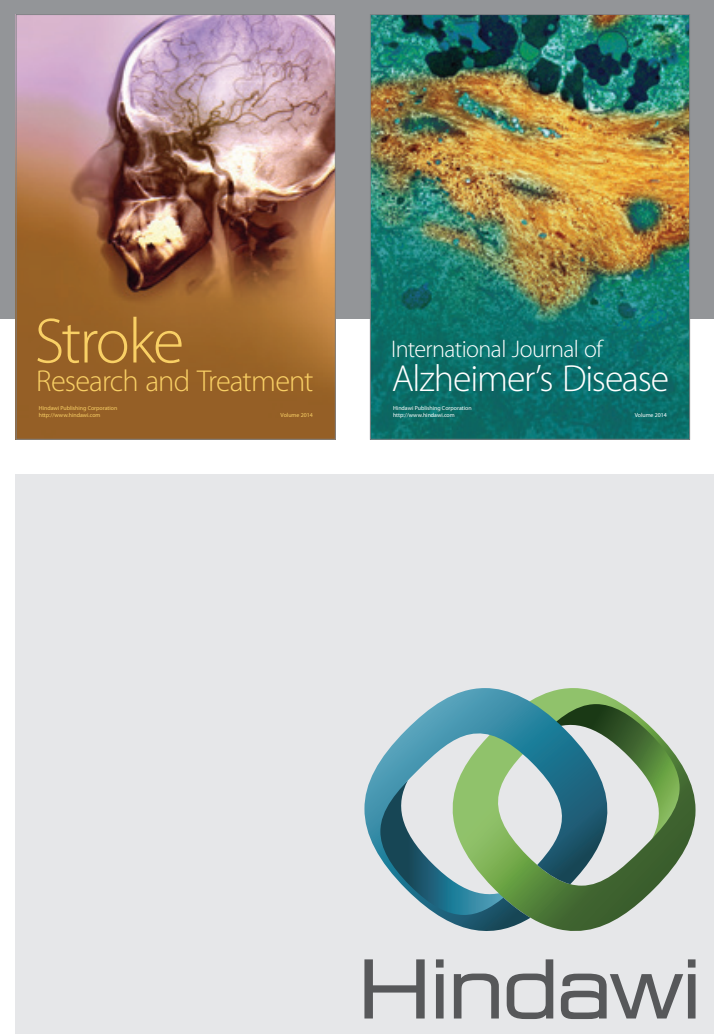

Submit your manuscripts at

http://www.hindawi.com
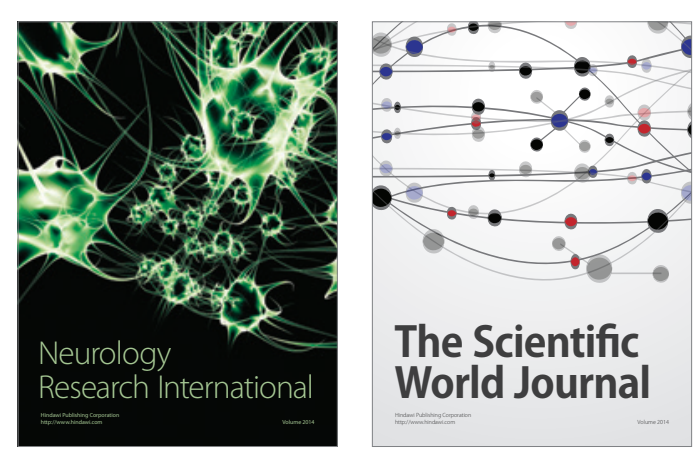

The Scientific World Journal

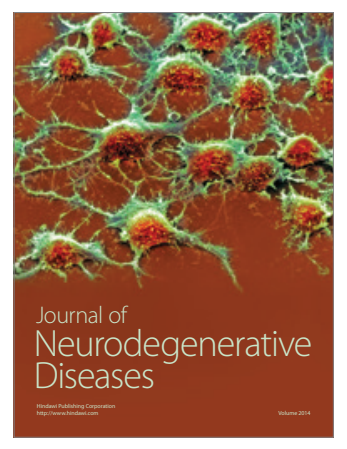

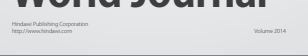

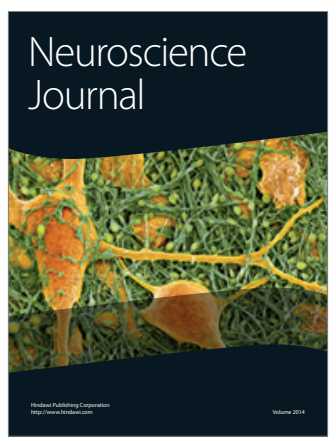

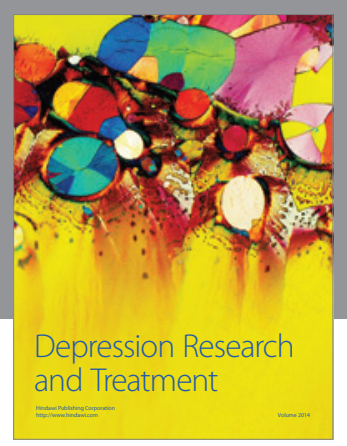
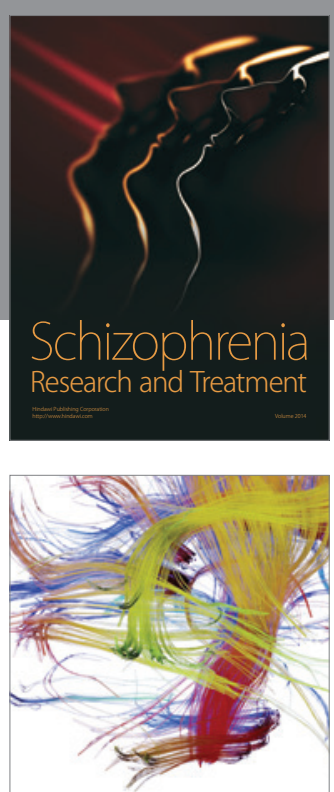

Brain Science

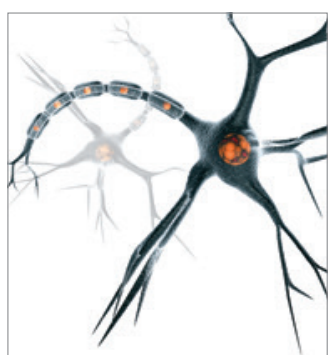

Neural Plasticity
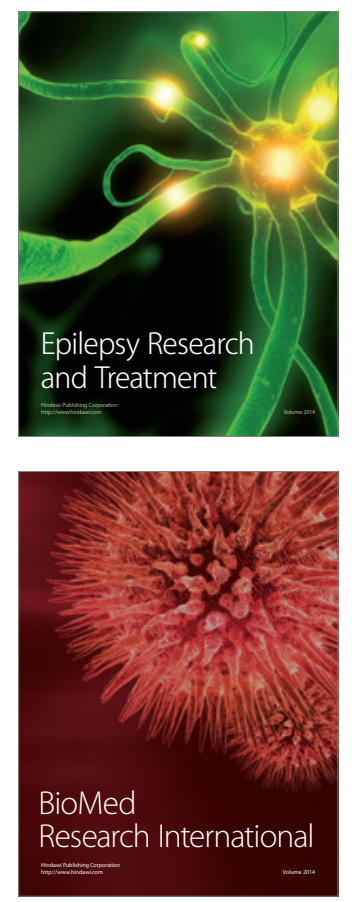

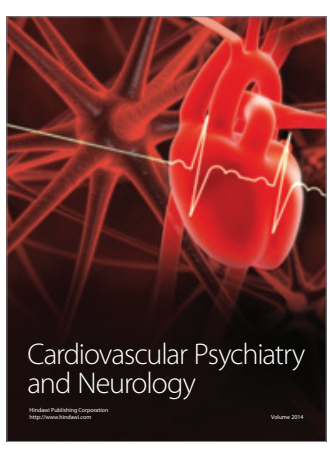

Parkinson's

Disease
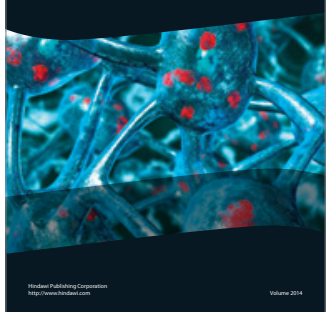